\title{
Decommissioning Schemes and Capacity Adjustment: A Preliminary Analysis of the French Experience
}

\author{
Olivier Guyader*, Patrick Berthou** and Fabienne Daurès* ${ }^{* 1}$ \\ French Institute for the Sustainable Exploitation of the Sea (IFREMER) \\ * Marine Economics Service, ** Fisheries Resources Department \\ BP 70, 29280 Plouzané - FRANCE \\ oguyader@ifremer.fr / pberthou@ifremer.fr /fdaures@ifremer.fr /
}

\begin{abstract}
:
The French decommissioning aims at permanently removing vessels from the fishing fleet according to European Union rules laid down within the Common Fisheries Policy. A system of premiums established by the French government is supposed to give the vessel-owners, the incentives to get rid of their fishing unit. This paper details the rules for the applicants and their evolution and it provides a preliminary analysis of the impact of these schemes over the 1991-2001 period. Special attention is paid to the characteristics of decommissioned vessels and of their owners. The problem of windfall gains of these policies is approached, and a first assessment is given. The consequences in terms of capacity adjustment are discussed according to the Multi Annual Guidance Programs defined at the Community level and to the limited entry system implemented at the national level. The inconsistencies and potential benefits of the policy of capacity adjustment are finally discussed.
\end{abstract}

Key words: Decommissioning schemes, buyback, capacity, fisheries, premium, MAGPs, limited entry JEL classification: Q22

\section{Introduction}

The French fishing fleet is one of the most important in Europe (Anon 2003). The fishing vessels mainly operate in the North East Atlantic area, harvesting stocks partly shared with the fleet of other European Union member states. In order to manage these common-pool resources, the Common Fisheries Policy was implemented at the beginning of the 70 s to promote the rational or sustainable exploitation of fisheries resources (Holden 1994). In 1983, the so called conservation policy decided by the Fisheries Ministers Council provided the basis for TACs and national quotas setting. The structural policy laid down the thread for achieving a sustainable balance between fishery resources and their exploitation (Hatcher 2000). Successive independent reports on the state of fish stocks in Community waters provided recommendations for significant reductions in fishing mortality and fleets levels in order to achieve the previous objective (Anon 1990; 1996). Adverse effects on fishing stocks of overcapacity have led to strengthening the role and hardening the constraints of Multi Annual Guidance Programmes (MAGPs). Implemented in 1983, their objectives were to control and reduce the capacity of the European fishing fleets by using common and agreed rules ${ }^{1}$. The objectives of fleet evolution were then expressed in engine power $(\mathrm{kW})$ and tonnage (GRT and more recently GT measures). Each member states were assigned to adjust their national fleet or subfleets according to general levels defined by the Fisheries Council and MAGPs approved by the Commission. The package of Community structural measures adopted in 1983 included a system of financial

\footnotetext{
${ }^{1}$ This research was funded by the Bay of Biscay Research Program. The opinions expressed here represent those of the authors and do not necessarily represent the views of Ifremer.
} 
aid for removal as well as a new scheme for the provision of vessel construction and modernization grants. This system was altered in order to further encourage overall reduction in capacity (Hatcher 2000). Faced by the increased tightening of MAGP objectives, the member states have implemented different types of public policies and decommissioning programs to fulfil fleet capacity reduction targets (see Frost et al. (1995) and Nautilus (1997) for examples). French decommissioning schemes - e.g. buyback program - were implemented in the beginning of the 90 s to permanently remove vessels from the fishing fleet. The objective of this paper is to review the French experience in decommissioning schemes and to provide a preliminary assessment of the schemes in terms of capacity adjustment.

The paper is organized as follows. Section 1 presents the main French fleet characteristics in terms of segments as well as the successive MAGP objectives. This is followed by an analysis of the framework of the different decommissioning programs and of the system which has aimed at limiting entry to the fisheries fleet. Section 3 details the characteristics of the vessels and vessel-owners who stayed or left and section 4 assesses the potential windfall gains captured by the elected vessel-owners. Section 5 tries to identify the results of these schemes in terms of capacity measures and we conclude with some remarks concerning the strength and the weakness of the policy for capacity adjustment, with special attention paid to decommissioning schemes.

\section{Fleet Structure and Multi Annual Guidance Programs}

In 2001, the French fleet yielded a $1 \mathrm{~B} \ln €$ value in landings and was distributed all along the Atlantic and Mediterranean coasts (MAPA and OFIMER 2002). A distant fleet of purse-seiners and bait boats targeting tuna also operates in the African tropical areas. The overseas fleets are, for the purpose of this paper, excluded from the next table. In 2001, the small scale fleet less than 12 meters represented around $75 \%$ of the vessel number. Most of them operate within the twelve nautical miles territorial sea from which the foreign fleets are in general excluded ${ }^{2}$. The $12-24$ meter vessels accounted for $21 \%$ of and respectively $40 \%$ and $35 \%$ of the total engine power and tonnage. The tonnage of the biggest length categories represented a significant share of the total tonnage ${ }^{3}$. According to E.C. regulation on MAGPs, the vessels were subject to an official segment allocation based on declared gears that mainly distinguished trawlers from non trawlers and purse-seiners. The non trawlers are mainly multipurpose vessels (Berthou et al. 2003).

Table 1. Distribution of the French Fleet per Segment and Vessels Length Categories in 2001

\begin{tabular}{|c|c|c|c|c|c|c|c|c|c|c|c|}
\hline Segment POP & $<7 \mathrm{~m}$. & 7-9 m. & 9-12 m. & 12-16 m. & 16-24 m. & 24-40 m. & $>40 \mathrm{~m}$. & Total & $\begin{array}{l}\% \text { of the } \\
\text { Vessels }\end{array}$ & $\begin{array}{l}\% \text { of total } \\
\mathrm{kW}\end{array}$ & $\begin{array}{l}\% \text { of total } \\
\text { GRT }\end{array}$ \\
\hline Coastal Vessels $<12 \mathrm{~m}$ & 653 & 780 & 662 & & & & & 2095 & $36 \%$ & $18 \%$ & $7 \%$ \\
\hline Trawlers $<30 \mathrm{~m}$ & 10 & 127 & 524 & 344 & 501 & 68 & & 1574 & $27 \%$ & $40 \%$ & $35 \%$ \\
\hline Trawlers $>=30 \mathrm{~m}$. & & & & & & 45 & 26 & 71 & $1 \%$ & $8 \%$ & $18 \%$ \\
\hline Non Trawlers 12-25 m. & & & & 138 & 108 & 2 & & 248 & $4 \%$ & $7 \%$ & $6 \%$ \\
\hline Non Trawlers $>25 \mathrm{~m}$ & & & & & & 9 & 1 & 10 & $0 \%$ & $1 \%$ & $1 \%$ \\
\hline Pelagic Trawlers > $50 \mathrm{~m}$. & & & & & & & 3 & 3 & $0 \%$ & $1 \%$ & $1 \%$ \\
\hline Coastal vessels* & 835 & 442 & 218 & 31 & 5 & & & 1531 & $27 \%$ & $10 \%$ & $3 \%$ \\
\hline Trawlers* & & & 2 & 9 & 75 & 55 & & 141 & $2 \%$ & $4 \%$ & $5 \%$ \\
\hline Purse Seiners* & & & 1 & 2 & 11 & 25 & 4 & 43 & $1 \%$ & $3 \%$ & $3 \%$ \\
\hline Bait boats & & & & & & 5 & & 5 & $0 \%$ & $0 \%$ & $1 \%$ \\
\hline Tropical Purse Seiners & & & & & & & 28 & 28 & $0 \%$ & $8 \%$ & $19 \%$ \\
\hline Total & 1498 & 1349 & 1408 & 523 & 700 & 209 & 62 & 5749 & $100 \%$ & $100 \%$ & $100 \%$ \\
\hline$\%$ of Vessels & $26 \%$ & $23 \%$ & $24 \%$ & $9 \%$ & $12 \%$ & $4 \%$ & $1 \%$ & $100 \%$ & & & \\
\hline Vessel Engine Power (kW) (\% & $6 \%$ & $11 \%$ & $19 \%$ & $12 \%$ & $27 \%$ & $12 \%$ & $15 \%$ & $100 \%$ & & & \\
\hline \begin{tabular}{|l|l} 
Vessels Tonnage (GRT) $(\%)$ \\
\end{tabular} & $2 \%$ & $4 \%$ & $8 \%$ & $9 \%$ & $26 \%$ & $18 \%$ & $33 \%$ & $100 \%$ & & & \\
\hline
\end{tabular}

* Mediterranean sea - Source: based on information provided by the Ministry of Agriculture and Fisheries (DPMA)

The MAGP\#1 (1982-1986) included targets for fleet capacity to be achieved, and the aim was merely to balance investments with removals in order to keep overall capacity at 1982-3 levels. From 1987 to 1991, MAGP\#2 assigned to each national fleet a reduction of 3\% in tonnage and $2 \%$ in engine power compared to the objectives which should be achieved by the end of 1986 under previous programmes. The main problem encountered in carrying out the MAGPs, especially during the first and second programs, was the fleet census and the measurement of the based physical indicators. The reference fleet for 1983 to establish the reduction in terms of engine power and tonnage evolved over time ${ }^{4}$. This reference was an increase of $20 \%$ in engine power and $10 \%$ in tonnage for the whole fleet. However, the adjustments were not homogenously distributed between the fleet segments, defined in terms of vessel size categories under MAGP\#1 (19831986 ) and \#2 (1987-1991). The growth nearly reached 30\% for the less than 12 meters segment and only $7 \%$ 
for the vessels belonging to the more than 40 meters segment. The first consequence was that the reduction objectives of $3 \%$ in tonnage and $2 \%$ in engine power required to withdraw more vessels than initially forecasted. However, the change in fleet size allowed the member state to keep a higher fleet level than expected at the end of the second programme. The second consequence was the changes in fleet size and structure gave incentives to the member state to modify the reduction objectives of the different segments. The capacity reduction in percentage was consequently mainly directed to the less than 12 meters even when this segment would initially be supposed to be stabilized over the period.

After a 1992 transition year, a new approach to the setting of fleet reduction targets was adopted over the 1993-1996 reference period and a global $15.5 \%$ decrease in engine power $(128,000 \mathrm{~kW})$ was required ${ }^{5}$. It involved the segmentation and the setting of different targets for each segment. Reductions of $21.2 \%$ should be applied to the Atlantic trawlers segments. The vessels using dredge gears were also levied with a $16.2 \%$ reduction in engine power ${ }^{6}$. A small increase in tonnage and a decrease of engine power was required for other segments. The member states had to achieve the effort reduction by capacity reduction but they could also implement activity reductions (days at sea) to reach these objectives. Contrary to the Netherlands or the United Kingdom, the French government has never used this tool.

The fisheries Council agreed for the MAGP\#4 over the 1997-2001 period. Finally, reductions in fishing effort of $30 \%$ were required, for the stocks with a risk of depletion, of $20 \%$ for stocks considered as overfished and zero increase for other stocks. In fact, a weighted reduction was applied to the above segments by taking into account the catch composition of the fleet segments. The overall reduction for the French fleet under the MAGP\#4 was of 5\% in engine power for a total amount of $60,000 \mathrm{~kW}$ and more if we take into account the delay of MAGP\#3. The reductions were heterogeneous in scale with a maximum rate of $18.8 \%$ for the non-trawlers of more than 25 meters and only $5.3 \%$ for the non trawlers between 12 and 25 meters ${ }^{7}$. According to the Common Fisheries Policy reform, the end of MAGP\#4 was postponed by the end of 2002. Moreover, the Fisheries Council decided in 2002 to forbid subsidies to building and modernization by the end of 2004. The counterpart of the possibility to subsidize the fleet investment for this period was to reduce the capacity of the French fleet by $3 \%$.

\section{Decommissioning Schemes in a Limited Entry System}

The management of capacity in France has been based on two mechanisms which on one hand aims at removing vessels from the fleet by incentives mechanism to exit, on the other hand to control administratively the entry to the fleet. Entry to the French fishing industry was considered by the Law as free before the decision in 1988, to create an operation permit, namely a "permis de mise en exploitation" or $\mathrm{PME}^{8}$. This system aimed at limiting entry flows to the French commercial fleet and became the main regulatory tool on the basis of which MAGPs were implemented ${ }^{9}$. Each new capacity project has been subject to an operation permit issuing. Capacity projects consist of; new buildings, importations of vessels, entries of vessels previously used for non-commercial fishing activity, change of the fishing capacity by an increase in vessel tonnage or increase in engine power, readmitted vessels which were not active for a six month period or nine months for vessels less than 12 meters. This system excludes vessels engaged in conchyliculture, kelps, corals and sponges harvesting. In 2000, the decree was amended and changed in the administrative area (e.g. from the Atlantic to the Mediterranean area) or in fleet segment has been submitted to permit holding.

Based on this regulation, the ministry of fisheries defines the annual allowance of engine power, and more recently, of tonnage that could be issued for each year. This allowance is shared between two vessel categories, more or less than 25 meters, with a split by region for the last category. The fleet segment criterion has been added to the sharing rules since 2000. It has also distinguished the project involving the renewal of vessel without capacity increase from others. The final allocation of operation permits is decided either at national level, by the ministry of fisheries for the biggest fishing units, or at regional level for the smallest vessels, by administrative authorities and after a consultation of professional organizations. Each so called "coremode" established the rules in compliance with which the operation permits are awarded to applicants, at a regional level. The next table provides an indication of the level of total allowable operation permit per year which was not necessarily allocated to applicants. Moreover, these amounts include capacity 
projects of fishermen who have scrapped non-decommissioned vessels to build a new vessel or buy a bigger one on the second hand market.

Table 2. Evolution of the Total Allowable Operation Permits in Terms of Engine Power (kW)

\begin{tabular}{|l|c|c|c|c|c|c|}
\hline Years & 1993 & 1994 & 1995 & 1996 & 1997 & 1999 \\
\hline Less than 25 m. & 21,700 & 22,000 & 15,600 & 4,150 & 10,900 & 22,868 \\
\hline More than 25 m. & 6,300 & 9,500 & 10,400 & & 4,100 & 4,417 \\
\hline Total & 28,000 & 31,500 & 26,000 & & 15,000 & 27,285 \\
\hline
\end{tabular}

Decommissioning schemes organized by the Ministry of agriculture and fisheries consist of a premium (subsidies) delivered to vessel owners to permanently remove their fishing unit from commercial fishing activity in European waters. The decision to scrap a vessel is not mandatory but depends on the fishermen's willingness to part with their fishing unit. Contrary to the United Kingdom decommissioning system which is based on a tendering system to select the applicants (Nautilus 1997), the level of premium French schemes is defined by the administration and revised for each scheme. The design of these schemes has to obey the E.C. regulations regarding eligibility criterion as a minimum age of vessel (10 years old) or the maximum level of premium subsidy amount per size category of vessels (e.g. tonnage categories). The age of a vessel is calculated on the first entry in the fishing industry. Other restrictive criterions have to be considered. For example, a minimum level of vessel activity is required (75 days per year) over the last two years and the vessels withdrawn had to be at least 9 meters in perpendicular length or 12 meters in the case of trawlers.

According to E.C. regulation, permanent removal concerns vessels to be demolished, to be used for noncommercial fishing activities or to be transferred to non E.U countries. Vessels with a tonnage under 25 GRT could not be exported to third countries. On the other hand, vessels removed from the fishing fleet file and the capacity withdrawn can not be used by elected fishermen for new capacity projects as defined previously. Until now, any eligibility criterion has been used to choose vessel-owners applicants ${ }^{10}$. The registration order is the rule for selecting the eligible applicants providing that the budget ceiling is not reached. Social measures may benefit the crew members as transitory incomes before retirement (for the oldest fishermen) or incomes equivalent to a certain amount if they have contributed to the unemployment insurance funds. The elected applicants have also to contribute to a so called "social solidarity fund" to share the cost of these measures ${ }^{11}$.

A series of decommissioning schemes have been implemented nearly every year since 1991 . There schemes were regularly implemented to fulfill the MAGPs intermediate and final MAGPs targets or when delays appeared. Consideration of the segments or of the vessels landings criterion was progressively included in these schemes. The first scheme known as the "Mellick plan" was the biggest. It was implemented in 1991 to cancel the delay of the MAGP\#2. The dedicated budget concentrated around $70 \%$ of the total public expenses over the 1991-1996 period. In 1993 and 1995, the budget available to the decommissioning scheme was too low to accept all the eligible applicants. The 1998 decommissioning scheme was supposed to discharge the delay of the MAGP\#3 $(20,000 \mathrm{~kW})$ and to achieve the intermediate objective of the MAGP\#4. Only vessels belonging to specific segments were eligible for this scheme and the following plans covering the years 1999 and 2000 were even more selective ${ }^{12}$. The 2000 and 2001 years were less restrictive to applicants but a specific scheme was organized in 2001 to remove the Atlantic vessels subject to the driftnet ban for tuna harvesting. The last scheme covers the period 2003-2004 and is the first one providing bigger financial incentives to vessels targeting significant species for which the stocks are considered to be in a bad state or stocks are subject to restoring plans. The premium scaling ranges respectively from $95 \%$ to $110 \%$ of the maximum amount authorized by E.C. regulation when a $65 \%$ rate premium is provided for other eligible applicants. Moreover, the budget sharing gives preference to the first category with $67 \%$ of the total amount allocated $(30 \mathrm{~m} €)$. 
Table 3. Evolution of the Public Subsidies to French Fleet (in Constant Euros 2002 including E.U. Funding)*

\begin{tabular}{|c|c|c|c|c|c|c|c|c|c|c|c|c|c|}
\hline Years & 1991 & 1992 & 1993 & 1994 & 1995 & 1996 & 1997 & 1998 & 1999 & 2000 & 2001 & 2002 & 2003-04 \\
\hline Investment-Modernization & 59 & 48 & 53 & 28 & 20 & 37 & 29 & 25 & 33 & 26 & 35 & 34 & \\
\hline Production Changes and Market Support & 11 & 13 & 13 & 23 & 24 & 11 & 13 & 8 & 9 & 10 & 9 & 11 & \\
\hline Reduction of the Production & 32 & 2 & 5 & 3 & 6 & 7 & 3 & 5 & 6 & 7 & 8 & 5 & $30^{\star \star *}$ \\
\hline Others $^{\star *}$ & 5 & 4 & 10 & 12 & 8 & 18 & 22 & 17 & 16 & 65 & 27 & 27 & \\
\hline Total & 107 & 67 & 80 & 66 & 59 & 74 & 68 & 56 & 62 & 106 & 78 & 78 & \\
\hline
\end{tabular}

Source: Ministry of Agriculture and Fisheries (DPMA) * excluding social security insurance and Public Collectives funding , ** geographical compensations, transitory subsidies, oil spill, ...*** forecasted budget

The total premium cost is shared equally between the member state and the European budget. In the French case, the regional public collectives, in other words districts and regions may add subsidies to the premium offered by the government with the national budget, as long as it does not exceed the European ceiling premium. This contribution of the regional collectives which are not responsible for fisheries management has probably declined over time for the reasons described below. The premium calculation is a function of tonnage categories expressed in terms of GRT and more recently GT measures. The premium amount is composed of a fixed part depending on each tonnage category and a variable part function of the real tonnage of each vessel. The fixed part increases with tonnage categories when the premium per GRT decreases with tonnage categories. As the tonnage is subject to higher variability for the biggest vessels, such a mechanism aims at smoothing the premium level for the biggest vessels. Moreover, the premium level was also increased for vessels for which the GRT/kW ratio was relatively low and under certain limits. Since the end of the $90 \mathrm{~s}$, the premium level has been subject to age criterion. This level declines with the age of the vessel to take into account wear and tear ${ }^{13}$.

The figure 1 presents the evolution of the minimum premium per engine power unit offered by the French government with the national budget to demolish vessels ${ }^{14}$. The incentives policy to fishermen has been structurally modified over the period with a marked increase in the minimum premium level. Its level held steady between 1991 and 1997 and it rose substantially between 1998 and 2001 to top in 2003 at a level close to the ceiling E.C. premium. The minimum premium in constant Euros offered by the government, including E.U. share, to scrap vessels belonging to the 9-12 meters category was around $160 € / \mathrm{kW}$ in 1991 , $314 € / \mathrm{kW}$ in 1999 and rose to $843 € / \mathrm{kW}$ in 2003.

Figure 1. Evolution of the Minimum Premium per Engine Power $(\mathrm{kW})$ Offered by the Government **

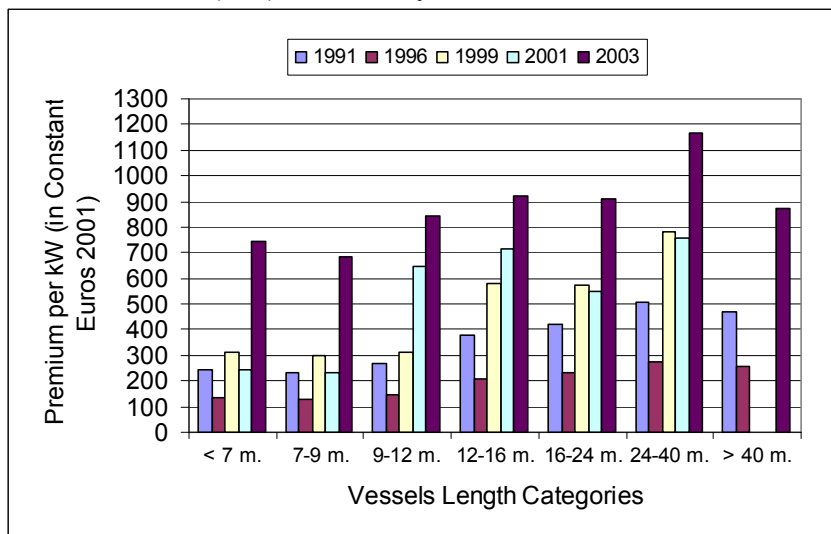

Figure 2. Evolution of the Effective Premium per Engine Power (kW) Received by the Vessel-owners*

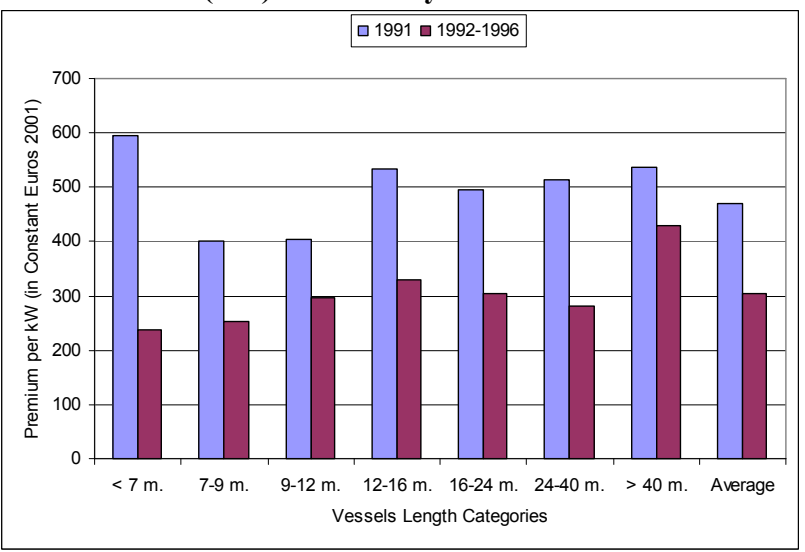

Source: based on information provided by the Ministry of Agriculture and Fisheries (DPMA) and Ofimer. In constant Euros 2001

* Total premium allocated by length categories / total kW of the removed vessels. ** Data no available for $>40 \mathrm{~m}$. (1991 and 2001$)$

Changes in premium also concern the levels offered to the different vessels tonnage categories and consequently length categories. In 1991 and 1996, the premium per kW rose steadily with vessels length categories. The situation evolved in 1999 with a strong improvement of the premium for the vessels with a length between 12 and 40 meters and especially for the 24-40 meters vessels. This evolution has to be linked to the objective of the 1999 decommissioning schemes which was to remove trawlers which mainly belong to these length categories. The upward adjustment in premium was applied to the 9-12 meters vessels in 2001 and the premium per $\mathrm{kW}$ became more homogenous between the length categories in 2003 and at its highest level. The figure 1 only provides an indication of the minimum premium offered to vessel owners 
and does not include the potential subsidies brought by the regional collectives. These actors may have played a significant role in the decommissioning policy in the funding context mentioned before, especially in the $90 \mathrm{~s}$ when the minimum premium proposed by the government was far from the E.C. ceiling premium. As figure 2 underlines, the 1991 premium received by vessels owners was, on average, multiplied by four for the less than twelve meters and more than double for the vessels between 12 and 24 meters. The more than 40 meters did not benefit from such an improvement. The funding of the removals by public collectivities declined relatively with vessel size. Moreover, the effective premium fall off between 1991 and the 19921996 period due to the decline in the funding involvement of the public collectivities.

Table 4. Contribution to the Total Premiums Amount per Funding

Source for the $50 \%$ Member State Share

\begin{tabular}{|l|c|c|}
\hline & 1991 & $1992-1996$ \\
\hline Government Funds & $62 \%$ & $75 \%$ \\
\hline Public Collectives Funds & $38 \%$ & $25 \%$ \\
\hline From Regionals Funds & $27 \%$ & $16 \%$ \\
\hline From Districts Funds & $11 \%$ & $8 \%$ \\
\hline
\end{tabular}

Source: Ofimer

These public collectives brought, on average, nearly $40 \%$ of the member state total premium funding when this rate fell to a $25 \%$ rate for the second reference period. This means that the success of the decommissioning depended on the financial effort of each regional and district authority to improve the premium level. The figures concerning the more recent period are not available but the public collectives share has likely been reduced for the reasons mentioned before. Nevertheless, this example underlines that the funding source of the decommissioning scheme is a key issue for the efficiency of such policies as collectives with free riding behaviors may not provide enough funds to reach national objectives.

\section{An Analysis of the Fishing Units and of the Vessel-owners Who Stayed in and Who Left}

This section describes, on the one hand the characteristics of fishermen population who decided to remove their vessel a given year, and on the other, the characteristics of the fishermen population belonging to the fleet at the beginning of the given year. The first decommissioning schemes implemented to fulfil the MAGP\#2 generated the most important number of removals. Around 922 fishing units were excluded in only one year and this represented $11.4 \%$ of the total fleet. The contribution to the decommissioning schemes of vessels belonging to the Mediterranean fleet was much lower than the effort of the Atlantic fleet. It represented respectively $5.9 \%$ and $15.9 \%$ of the population for the first plan.

Table 5. Evolution of the Number of Removed Vessels

\begin{tabular}{|l|r|r|r|r|r|r|r|r|}
\hline Years & 1991 & 1992 & 1994 & 1995 & 1996 & 1997 & 1998 & 1999 \\
\hline Decommisionned Vessels & 922 & 25 & 208 & 201 & 21 & 139 & 134 & $38^{*}$ \\
\hline Average Tonnage (GRT) & 13 & 85 & 27 & 20 & 9 & 14 & 24 & 9 \\
\hline Average Engine Power (kW) & 74 & 235 & 119 & 115 & 87 & 106 & 154 & 84 \\
\hline
\end{tabular}

* provisional data - Source: Ofimer/DSI

The first conclusion is that the vessels removed from the fleet were, on average, older than the vessels that stayed. In 1991, the mean age of the vessels was respectively 25.6 years compared to 15.1 years for the remaining vessels. As illustrated in the next figure, the most important share of the population of removed vessels was between 20 and 35 years old. However, $9 \%$ of the vessels from 10 to 20 years but around $27 \%$ of the vessels from 30 to 40 years left the whole French fleet. The average age of decommissioning did not change by far over the subsequent MAGP\#3 even if the fleet grew older. The average age of the fleet reached 19 years at the end of 1996. The more recent period shows an increase in average age of the removed vessels. It reached around 30 years in 1997 and 1998. Until recently, the decommissioning schemes have benefited the vessels which, for most of them were probably at the end of their life span or which required significant investment to be upgraded. 
Figure 3. Decommissioned Vessels/Initial Population as a Function Length Categories

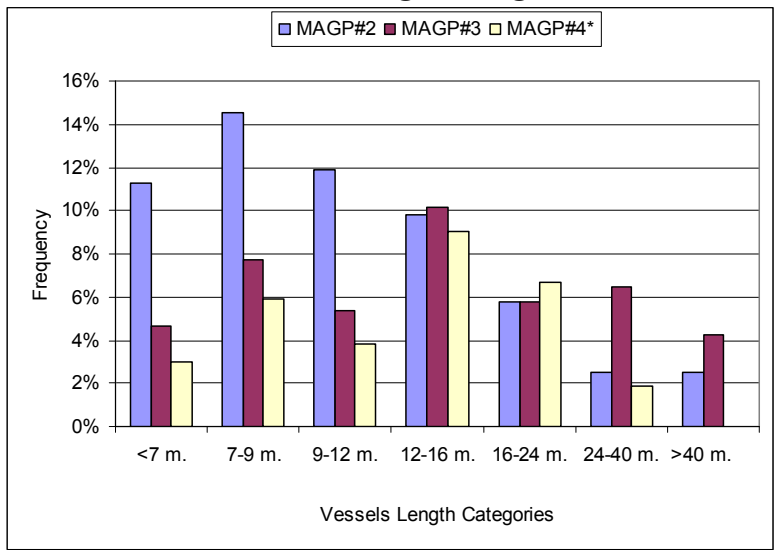

Figure 5. Vessels-owners/Initial Population as a Function of Age Categories

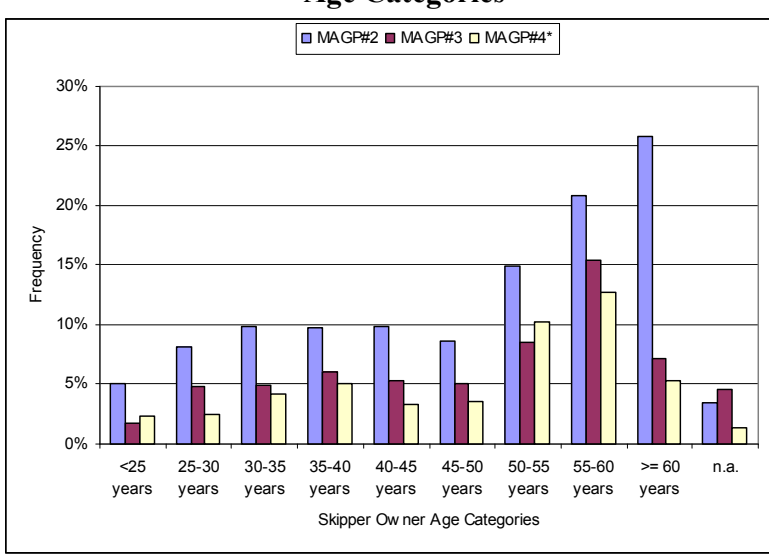

Figure 4. Decommissioned Vessels/Initial Population as a Function Age Categories

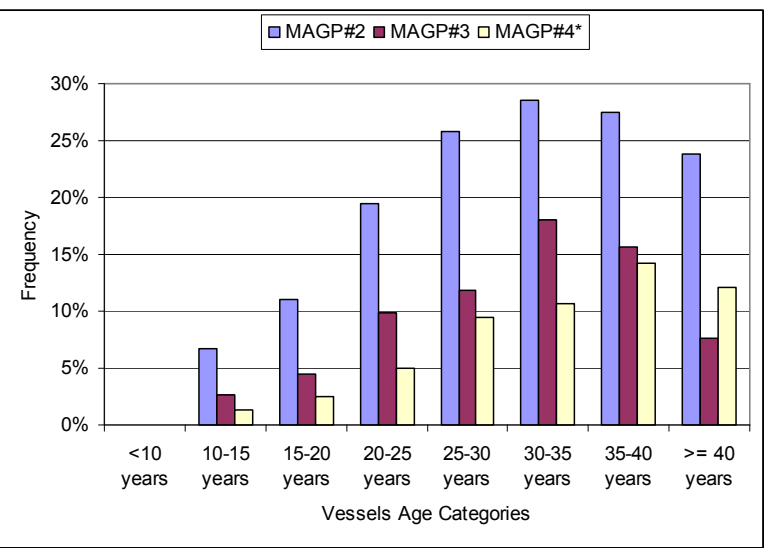

Figure 6. Vessels Owners per Age categories/Total Vesselowners

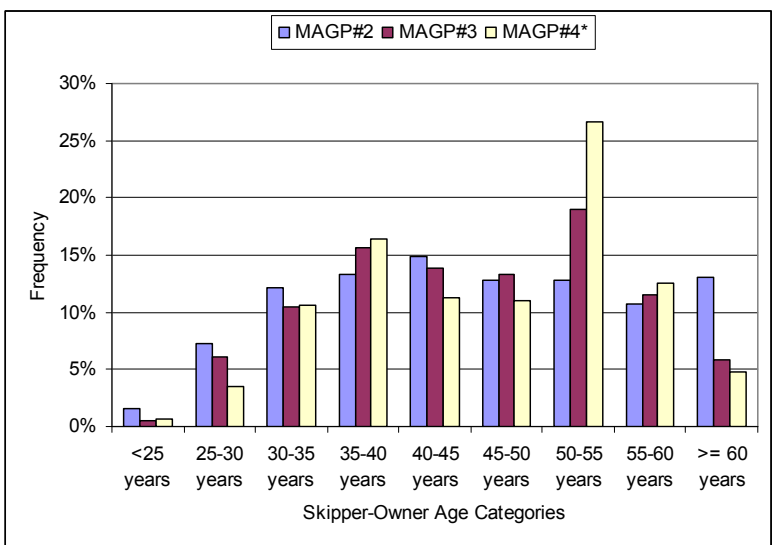

Source: Ofimer, DPMA-BCS-DSI

The first decommissioning schemes mainly favored the removal of the smallest vessels, whatever the physical characteristics considered; tonnage, engine power, length. $15 \%$ of the vessels removed belonged to the 7-9 meters category at the beginning of the year and the contribution to exit was the highest for the less than 12 meters long category. Within the MAGP\#3, the highest rate of exit concerned the 12-16 meters vessels and it reached around $10 \%$ of this length category. This rate ranged between a minimum of $4 \%$ for the more than 40 meters and a maximum of 7\% for 7-9 meters category. As a consequence, the average figures in terms of physical characteristics of the removed vessels got closer to the remaining fleet. The decommissioning schemes implemented for the MAGP\#4 have affected relatively more the 12-16 meters vessels (9.5\%) than the other categories. However, the 16-24 meters category is at the second level with a $6.8 \%$ rate and is followed by the 7-9 meters category with $6.4 \%$ of the total population removed in this category.

The following analysis focuses on the origin of the removed vessels in terms of fleet segments. The MAGP\#3 and \#4 reference periods are considered even if the information used does cover the end of MAGP\#4. Allocation in the fleets segments of the vessels removed from the fleet under MAGP\#1 is not available, because the segmentation based on gears used or declared was not in force in 1991. However, we have seen previously that the most important share of the decommissioned vessels in 1991 came from the less than 12 meters categories, especially the vessels less than 9 meters. Most of these vessels were not trawlers and would not have to be decommissioned under MAGP\#3 rules as the reduction of capacity mainly concerned trawlers and, to a lesser extent, dredgers. The subsequent removed vessels were under the basis of fleet segmentation using vessels gears. 
Table 6. Segments of the Removed Vessels

\begin{tabular}{|l|r|r|r|r|r|r|}
\hline & Number of Vessels & Tonnage (GRT) & Engine Power (kW) \\
\hline & $1992-1996$ & $1997-1999$ & $1992-1996$ & $1997-1999$ & $1992-1996$ & $1997-1999$ \\
\hline Trawlers & $37 \%$ & $37 \%$ & $70 \%$ & $55 \%$ & $62 \%$ & $56 \%$ \\
\hline Non Trawlers & $63 \%$ & $63 \%$ & $30 \%$ & $45 \%$ & $48 \%$ & $44 \%$ \\
\hline Dredgers & $24 \%$ & $26 \%$ & $8 \%$ & $8 \%$ & $15 \%$ & $15 \%$ \\
\hline \multicolumn{7}{|c|}{ Number of observations: respectively 404 and 311 for the period 1992-1996 and 1997-1999 } \\
Source: Ofimer
\end{tabular}

Around $37 \%$ of the decommissioned vessels were trawlers whatever the period considered. As French trawlers are generally bigger in size than non trawlers, the removed capacity in terms of $\mathrm{kW}$ or GRT is higher, especially under the first period where few big trawlers were excluded from the fleet. On the other hand, there is no statistical difference between fleet segments concerning the age of the removed fishing unit age and the age of vessel owners.

As underlined in the next table, around $95 \%$ of the vessels were scrapped and only $2 \%$ exported to nonEuropean waters under the decommissioning schemes covering the period 1991-1996. However, the 31 exported vessels represented respectively $11 \%$ and $21 \%$ of the total engine power and tonnage removed. As previously presented, the European regulation defined a minimum size under which the vessel can not be exported.

Table 7. Utilisation of Removed Vessels Over the Period 1991-1996

\begin{tabular}{|l|r|r|r|}
\hline Removed Vessels & Vessels Number & Tonnage (GRT) & Engine Power (kW) \\
\hline Demolished Vessels & $95 \%$ & $75 \%$ & $84 \%$ \\
\hline Exportation & $2 \%$ & $21 \%$ & $11 \%$ \\
\hline Other non Fishing Activites (Commerce) & $1 \%$ & $2 \%$ & $2 \%$ \\
\hline Other non Fishing Activites (Yachting) & $2 \%$ & $2 \%$ & $3 \%$ \\
\hline Total & $100 \%$ & $100 \%$ & $100 \%$ \\
\hline \multicolumn{4}{|c}{ Sample of 1357 vessels } \\
Source: Ofimer
\end{tabular}

Finally, the reduction of the fleet size may be "natural" as vessel owners decide to get rid of their vessels by selling it to other countries or to bodies not using the vessel for commercial fishing activities. Even if the figures on these exits are not available, the scrapping of the vessels without using decommissioning schemes has probably become less common.

The figure 5 presents the age structure of the skipper/owners, who decided to scrap their fishing unit as a function of the total population (population remaining and population removed). The general shape shows that the frequency of elected fishermen was low for the youngest fishermen but increased slightly with age to reach a maximum for the 35 and 40 years category. Around $10 \%$ of the fishermen of this age withdrew their vessels under MAGP\#2. This rate decreased slightly between 40 and 50 years and picked up after 50 years. This is especially the case for the first scheme under which, $25 \%$ of the population of more than 60 years removed their vessels. The evolution was quite similar under MAGP\#3 and 4 except for the oldest skipper/owners who represented only $5 \%$ of the removed vessels. For MAGP\#4, more than $25 \%$ of the elected skipper/owners were between 50 and 55 years which is the legal date for retirement. The conclusion is that decommissioning schemes benefited mainly the skipper/owners who were either at the end or to a lesser extent at the middle of his working life. After the removal of their fishing unit, a significant rate of the skipper/owners has stayed in the fishing industry. More than 30\% of them hold another fishing vessel but there is no information on the status of those who definitively left the fishing industry ${ }^{15}$. For the former, the application to the decommissioning scheme is part of their strategy to stay in the fishing fleet. With a $23 \%$ rate, the 35 to 40 skipper/owners age category was the most represented within the vessel-owners population who decided to stay. 
Table 9. Distribution by Age Categories of the Skipper/owners Who Scrapped their Vessels to Operate Another Vessel

\begin{tabular}{|c|c|c|c|c|c|c|c|c|c|c|c|}
\hline Age categories in years & $<25$ & $25-30$ & $30-35$ & $35-40$ & $40-45$ & $45-50$ & $50-55$ & $55-60$ & $>=60$ & n.a. & total \\
\hline$\%$ of the Population & $2 \%$ & $9 \%$ & $16 \%$ & $23 \%$ & $18 \%$ & $15 \%$ & $9 \%$ & $4 \%$ & $2 \%$ & $3 \%$ & $100 \%$ \\
\hline$\%$ by Age Category & $50 \%$ & $45 \%$ & $44 \%$ & $49 \%$ & $40 \%$ & $37 \%$ & $16 \%$ & $10 \%$ & $6 \%$ & $43 \%$ & $31 \%$ \\
\hline
\end{tabular}

Source: Based on Ofimer

The age seemed to be crucial in the decision to stay, however there is no significant difference in the rate of staying before 45 years. Around $45 \%$ of fishermen who decided to remove their vessel have re-invested or kept another vessel over the period. Then, this rate declined to $16 \%$ and finally $6 \%$ for the eldest. As a synthesis, decommissioning schemes have given incentives to exit to the smallest vessels, especially those of less than 12 meters within the first schemes. Then, the following vessels category $(12-16 \mathrm{~m}$.) were also affected by the second scheme at a significant rate. The vessels belonging to the 16-24 $\mathrm{m}$ have been more recently concerned by the more recent schemes at a lower level but at a similar rate compared to the smallest units. These schemes have mainly benefited the oldest fishing units and the ageing of the fleet over the period has contributed to the supplying of the oldest cohorts. Even if $70 \%$ of the vessel-owner decided to leave the fishing industry, the others have used this public policy as an opportunity to stay in the fleet.

\section{A Preliminary Assessment of Windfall Gains}

The question of windfall gains is crucial in the implementation of public policies and especially decommissioning schemes. It is a key issue in the assessment of these policies in terms of cost-efficiency analysis. By windfall gains, we mean the transfer payments from public budget (tax payers) to fishermen higher than their minimum willingness to receive in order to leave the fishing industry or to remove their fishing units. Of course, the objective of these public policies objectives could be based on distributional considerations, so that transfer payments provide a better sharing of the wealth. Until now, no explicit reference to the previous objective has been advanced in the French decommissioning policy. Between 1990 and 2000, the first objective was to reach the MAGPs objectives in order to get the possibility to renew the fleet. Considering a limited budget to reduce capacity, the problem could be to lay down the premium offered to the fishermen at the required level, in order to remove the maximum amount of the fleet engine power and tonnage.

The next table provides an analysis of the real premium per engine power allocated to the eligible applicants under MAGP\#2 and MAGP\#3 periods. Only the vessels which belong to the Atlantic area are hereafter considered. Compared to these figures are the estimated market prices per engine power of the same eligible vessels. The estimated market price comes from a hedonic analysis of second-hand market transactions prices over the 1985-2000 period (Guyader et al. 2003) ${ }^{16}$. The figures below do not take into account the vessels segment but it was estimated that trawler prices were, on average, $20 \%$ more expensive than non trawlers. As a consequence, the price probably overestimates the estimated price for non-trawlers vessels which represents a significant share of the removed vessels. Premiums offered were generally higher than the vessels prices on the second hand market and the highest difference is especially noticed for 1991. The estimated windfall gains were around 5 Millions Euros. The relative difference was much higher (47\%) for the vessels less than 7 meters and more homogeneous (between 16 and 28\%) for the subsequent vessels length categories. 
Table 10. Comparison of the Premium of Withdrawn Vessels and their Estimated Price on the Second Hand Market.

\begin{tabular}{|c|c|c|c|c|c|c|c|}
\hline Years & Indicators in Million Euros 2002 & $<7 \mathrm{~m}$. & $7-9 \mathrm{~m}$. & $9-12 \mathrm{~m}$. & $12-16 \mathrm{~m}$. & $16-24 \mathrm{~m}$. & Total $^{*}$ \\
\hline \multirow{3}{*}{1991} & Premiums value & 2,9 & 5,8 & 6,6 & 5,4 & 5,4 & 26,1 \\
\hline & Vessels market value & 2,0 & 4,7 & 5,6 & 4,2 & 4,6 & 21,1 \\
\hline & Difference in \% & $47 \%$ & $25 \%$ & $18 \%$ & $28 \%$ & $16 \%$ & $24 \%$ \\
\hline \multirow{3}{*}{1992} & Premiums value & & 0,1 & 0,1 & 0,1 & 0,2 & 0,6 \\
\hline & Vessels market value & & 0,1 & 0,1 & 0,1 & 0,3 & 0,6 \\
\hline & Difference in $\%$ & & $30 \%$ & $19 \%$ & $13 \%$ & $-28 \%$ & $-3 \%$ \\
\hline \multirow{3}{*}{1994} & Premiums value & 0,2 & 0,9 & 1,0 & 2,6 & 2,2 & 7,0 \\
\hline & Vessels market value & 0,2 & 0,7 & 0,7 & 2,0 & 2,5 & 6,2 \\
\hline & Difference in \% & $17 \%$ & $34 \%$ & $31 \%$ & $28 \%$ & $-12 \%$ & $12 \%$ \\
\hline \multirow{3}{*}{1995} & Premiums value & 0,3 & 0,8 & 1,1 & 1,2 & 1,3 & 4,6 \\
\hline & Vessels market value & 0,3 & 0,6 & 0,7 & 1,3 & 1,4 & 4,3 \\
\hline & Difference in \% & $3 \%$ & $32 \%$ & $43 \%$ & $-10 \%$ & $-7 \%$ & $7 \%$ \\
\hline \multirow{3}{*}{ 1991-1995 } & Premiums value & 3,4 & 7,6 & 8,8 & 9,3 & 9,1 & 38,2 \\
\hline & Vessels market value & 2,4 & 6,0 & 7,2 & 7,7 & 8,9 & 32,2 \\
\hline & Difference in \% & $40 \%$ & $26 \%$ & $22 \%$ & $21 \%$ & $3 \%$ & $19 \%$ \\
\hline
\end{tabular}

Source: Based on Ofimer and Affaires Maritimes * Vessels more than 24 meters are excluded

The margin between the indicators was reduced for the next years with a $12 \%$ and $7 \%$ difference in 1994 and 1995 but the less than 12 meters categories benefited from substantial windfall gains compared to the other categories. The negative difference for the 16-24 m. category after 1991 can be explained by the fact that some vessel-owners were compelled to remove their vessels because of their bad economic situation, rather than selling their fishing units on the second hand market (see below).

Based on the mentioned statistical analysis, the figure 7 shows the evolution of vessel prices on the second hand market. The example of a theoretical vessel [10 GRT] with three different year classes is used. No ageing effects due to wear and tear are considered over the period so that the only annual effects are embodied in this evolution. The price rose steadily over the 1985-1991 period and began to fall in 1992 to reach a trough in 1993. This significant decline is explained by the slump that faced the French fleet in this last period. Then, the vessels prices hold steady between 1994 and 1996 and the price climbed to very high levels in 2000. The 100\% increase in vessel price between 1993 and 2000 cannot be explained by new investment in vessel but by the capitalization of operation permit implicit value in vessel prices. According to this result, Guyader et al. (2003) quantified the evolution of the Atlantic fleet value and split the capital stock, in a material value of fishing units and an immaterial value embodied in the vessel transaction price. As mentioned previously, the entry to the fishing industry is subject to operation permit holding but this right to harvest is not tradable except through the sale of the boat. As underlined in figure 8., the fall in fleet material value is mainly explained by the ageing of the fleet and the declining of its size. The increasing implicit value kept more than $50 \%$ of the vessel price in 2000 . This means that decommissioning schemes buyback not only the value of vessels but also the value of the permit.

Figure 7. Evolution of Price of a Vessel of Different Year Classes (No Ageing)

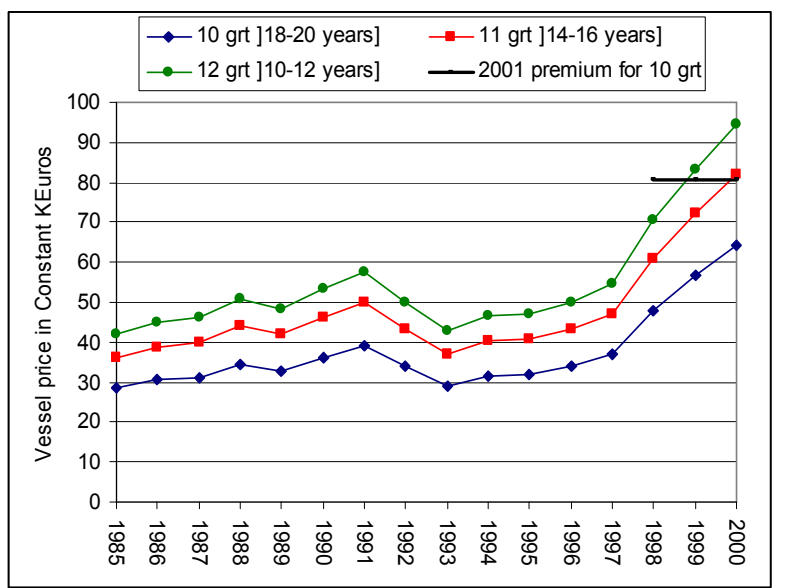

Figure 8. Evolution of the French Atlantic Fleet Value Including Material and Immaterial Value

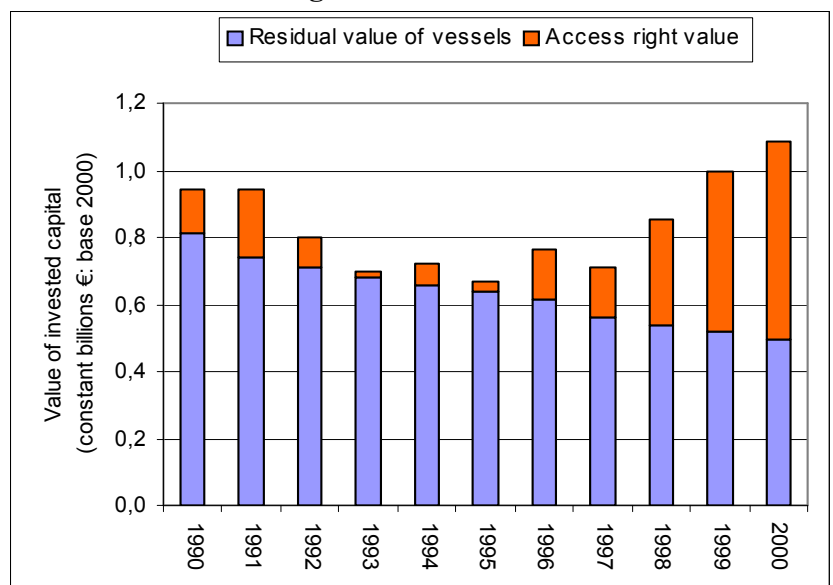

Source: based on information provided by the Ministry of Agriculture and Fisheries (DPMA) and Affaires Maritimes

The year limited allocation of new operation permits by the public authorities is free of charge for new entrants or for fishermen who would like to increase their vessel administrative capacity over the level of 
capacity merged by purchasing vessels on the second hand market ${ }^{17}$. In such a context, the elected fishermen to an operation permit may benefit from windfall gains due to their right to harvest the fishing resource but also of the potential windfall gains when they decide to scrap their administrative capacity under a decommissioning scheme. Except the vessels owners who decided to decommission their unit in 1991, the next applicants may be considered as relative losers as it would be more profitable for them to stay few more years in the industry so that they could take advantage of the marked increase in the vessels value. Finally, the government has adjusted the premium levels to the second hand market prices. This is rational because vessels owners decide or not to scrap their fishing unit by comparing the price of their fishing units on the second hand market and the premium offered by decommissioning schemes. The above figure shows the 2001 premium level compared to the market price of a vessel at different age. This means that the owners of the more recent vessels would not be interested in such schemes and only the 18-20 years vessels would be scrapped. The statistical influence of the premium levels on the second hand vessels prices has not yet been proved $^{18}$. However, the premium improvement has probably induced "ratchet effects" on the vessel price as the potential sellers take into account the premium level when they decide or not to get rid of the fishing unit.

\section{Impact of MAGPs and decommissioning schemes on fishing capacity.}

The entire problem regarding the impact of buyback or decommissioning schemes on fishing capacity is that it is difficult to distinguish the impact of these schemes from the impact of other regulations like the entry control system previously described or subsidies for investment to the fleet. Conversely, the question of what would have happened in a situation without the MAGPs and the decommissioning schemes is difficult to address considering the scope of this paper. The objective of this section is to give a preliminary description of the "fleet capacity" evolution according to engine power and tonnage indicators. The application of output capacity approach was only considered in a limited number of case studies and not to the whole fleet (see Guyader and Daurès 2002 in Vestergaard et al. 2002).

The French fleet was reduced by $53 \%$ in vessels number, $25 \%$ in tonnage and only $18 \%$ in official engine power between 1983 and 2001. Consequently, the average size of the remaining units rose, from 94 to 160 $\mathrm{kW}(+69 \%)$ and from 18 to 28 GRT $(+54 \%)$ and the main contribution to the increase concerned the $80 \mathrm{~s}$. The operation permit has played its role in rationing individual engine power. Nevertheless the real engine power of the vessels has probably been improved over the period and technical progress on gears and equipments has certainly reduced the impact of administrative capacity reduction on fishing mortality. Moreover, the size of passive gears has been significantly increased (see Morizur and Carn 2000). It is also interesting to consider the state of the fleet at the beginning of the $90 \mathrm{~s}$, before the implementation of the decommissioning schemes. The structure of the fleet was considerably influenced by the investment in new vessels in the 80 s, especially at the end of this decade. Significant cohorts of young fishing units entered the fishing fleet and most of them were subsidized by public funds especially under E.C. regulations agreed by the E.C. Fisheries Council (Boncoeur et al. 2000). More than 1500 vessels were less than 5 years old and around 1400 fishing units were in the 5-10 years category in 1991 (see figure 9). 

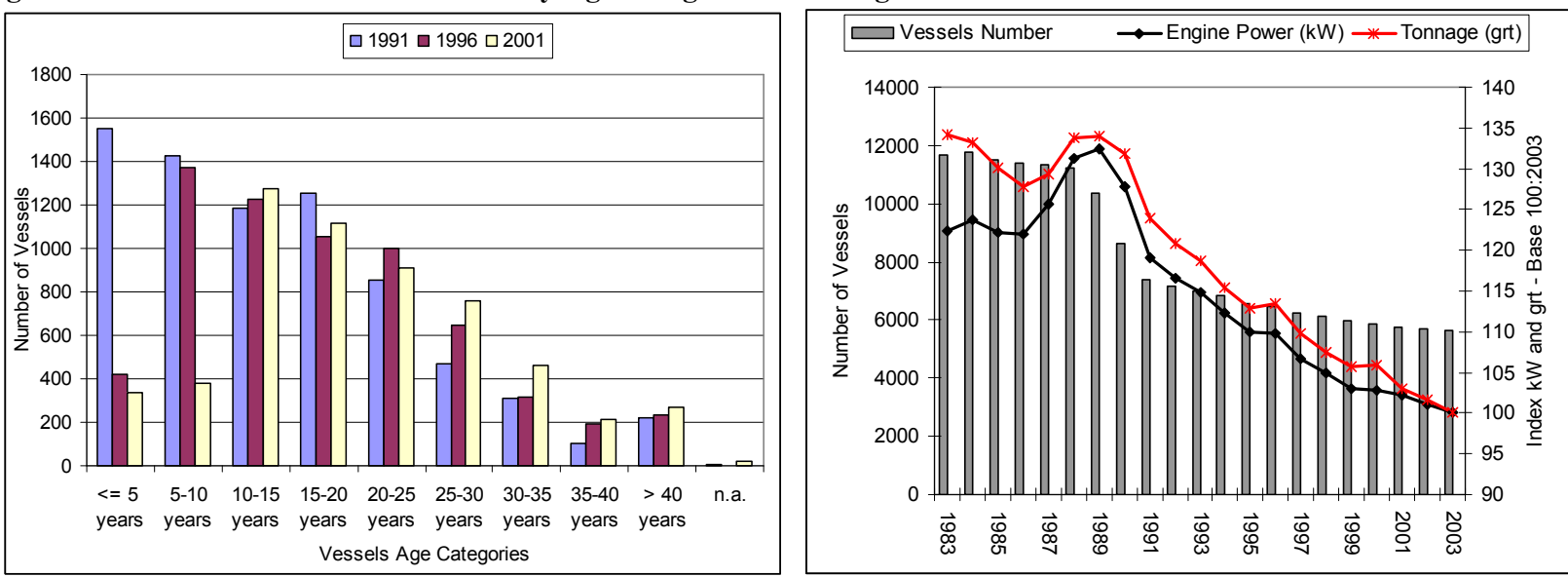

Source: based on information provided by the Ministryof Agriculture and Fisheries (DPMA)

The renewal of the fleet was then limited by the MAGPs and the rationing of operation permits at a national level. As a consequence, the age of the fleet went up, from a 17.3 years in 1991 to 21.9 at end of 2003. Over the 1991-1999 period, the net decrease in fleet size concerned around 2680 vessels for $222,000 \mathrm{~kW}$ and 42,000 GRT. A minimum of 1690 decommissioned vessels for 29,000 GRT and $163,000 \mathrm{~kW}$ have contributed to this fall. This represents at least $73 \%$ of the engine power reduction. The MAGPs forced the member state to fulfil their objectives in terms of "administrative" capacity reduction. It is, at this stage, difficult to measure the real impact of these policies either on the fishing mortality or on the state of the stock or on the rent exhausted from the fisheries. However, the state of a significant share of fish stocks in the North-east Atlantic is still considered to be in a bad state (ICES 2002).

The next figures present the evolution of the fleet not in terms of MAGPs segments but by merged segments; trawlers, non trawlers including dredger vessels, purse-seiners and bait-boat vessels operating from the Atlantic districts. Between 1991 and 2001, the decrease in vessel numbers was 1088 vessels (-21\%), from which $68 \%$ were non trawlers $(-24 \%$ in number) and $90 \%$ of them were less than 12 meters. Their contribution to capacity reduction was respectively limited to $12 \%$ and $17 \%$ in $\mathrm{kW}$ and GRT. Moreover, $49 \%$ of the reduction for these vessels occurred under MAGP\#3. As underlined before, many of these multipurpose vessels would not have to be removed under this program. The biggest vessels of this segment (24-40 m.) were more affected under MAGP\#4,

Figure 11,12,13,14,15,16. Evolution of the Fleet Size by Size and Segments Between 1991 and 2001 

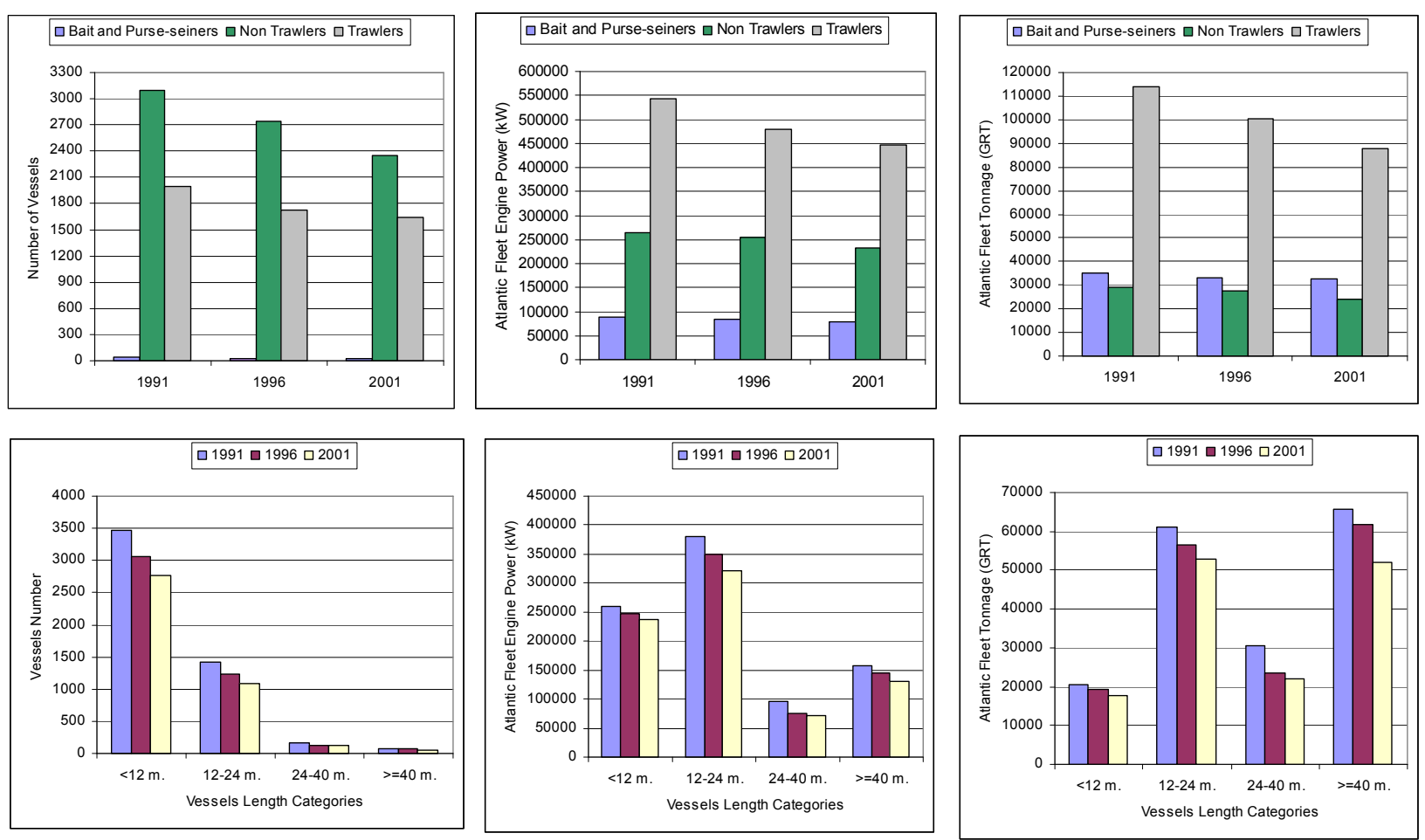

Source: based on information provided by the Ministryof Agriculture and Fisheries (DPMA)

Between 1991 and 2001, the reduction in trawler vessel numbers reached $17 \%$ and respectively $17 \%$ and $23 \%$ in $\mathrm{kW}$ and GRT. The $-24-40$ meters and more than 40 meters categories provided the most important decrease of this segment under MAGP\#3 with a $19 \%$ and a $17 \%$ reduction in vessels number. The reduction was the same for the 40 meters vessels under MAGP\#4 and the 12-24 meters vessels also contributed significantly to the reduction in capacity $(-12 \%)$. Conversely, the less than 12 meters trawler vessels benefited from an increase in number $(+8 \%)$. All the segments have contributed to fleet capacity reduction but with different magnitudes but it is difficult at this stage to assess the consequences on fishing mortality However, the residual material value of the fleet, especially the Atlantic fleet, was reduced from $0.8 \mathrm{~B} \ln €$ to around $0.5 \mathrm{Bln} €$ between 1990 and 2000. This decrease is explained by the capacity reduction in tonnage but also the ageing of the fleet over the period. Daurès et al. (2003) concluded that the correlation between age and turnover for the cross section data is negative. However, the effects of technical progress may have balanced the negative impact on the landings of age over the period considered.

\section{Strengths and Weaknesses of the Capacity Adjustment Policy.}

This section first tries to underline the consistencies of different measures implemented by the French capacity adjustment public policy. In 1995, the so called "Interministerial Committee for restructuring artisanal fishing fleet" (CIRPA) presented a financial program to help some of the fishing firms in a critical economic or financial situation. The declining profitability of the fleet in the beginning of the 90 s combined with a high level of debts for vessel owner who decided to invest a few years ago conducted to review 657 applicants. From the 380 eligible applicants, the public authorities decided to balance the liabilities of 140 fishing units. Other vessels were scrapped in decommissioning schemes. The former were sold on the second hand market and most of them were between 12 and 25 meters long and young trawlers harvesting in the Atlantic area (France-eco-pêche 1996). This represented around 11\% of the 12-25 meters fleet and respectively $40,000 \mathrm{~kW}$ and $6,000 \mathrm{GRT}$. At least $83 \mathrm{M} €$ were spent by the public budget to compensate the debts of the fishing firms. This public choice may be seen as inconsistent as the delay in MAGP\#3 capacity objective due to the trawlers segment reached a near $20,000 \mathrm{~kW}$ level in 1996 . It would have been costefficient to use the public funds to scrap these vessels rather than to subsidize them. Moreover, the public budget dedicated to decommissioning schemes has not only been used to pay for vessels material value but also to pay for the operation permit value. As shown before, this immaterial value was low or null between 
1993 and 1995, compared to the current levels. In retrospect, the public authorities could have saved money if they had decided to scrap vessels during this period rather than waiting for the end of the 90s.

The table 3 gives the evolution of the public subsidies given to the fishing industry between 1991 and 2003 . It is interesting to underline the fact that the global amount dedicated to investment was bigger than the amount of money allocated to decommissioning of the fishing fleet. The amounts allocated by the EU and French Government to decommissioning schemes represented only slightly more than $1 \%$ of the total expenditure of these authorities in aid to the fishery sector over the same period (Giguelay 1999). Boncoeur et al. (1998) assessed the influence of investment subsidies on the French fleet operating in the English Channels fisheries and concluded in the existence of a bias in favour of larger boats in the distribution of investment subsidies and, for a significant part of these vessels, a dependency of long term viability on subsidies. The E.U. Council decision to forbid the subsidization of the fleet investment at the end of 2004 would probably reduce the inconsistencies of the public policy from a capacity adjustment perspective.

The strengths and weaknesses of decommissioning schemes have to be assessed on the basis of MAGPs objectives. The problems of the selection of the applicants, as well as the way of laying down the premium have to be considered. Until 2003, neither the budget dedicated to the decommissioning schemes nor the premium levels were linked to the MAGPs objectives. It was then possible to scrap vessels belonging to fleets segments not concerned by capacity reduction or vessels capacity at a higher level than required by the regulation. At least, a bigger premium would have been given to vessels owners belonging to targeted segment rather than those belonging to non-targeted segments. The more recent decommissioning schemes have been improved from that point of view. Rules concerning the maximum age of scrapping could have been settled in order to avoid the funding of the oldest vessels. Proof of fishing mortality reduction (historical catches of the vessel scrapped) has only recently been used as a qualification criterion. In most of the cases, fishermen who have decided to scrap their vessel are able to re-invest the premium earned in the fishing industry. It is considered as difficult to limit this behavior as it is complex to control the capital of fishing firms. Finally, the fleet Register including the vessel characteristics and fleet belonging was not common knowledge. Neither fishermen and fishermen organizations nor citizens and non governmental organization have had the possibility to verify the implementation and the efficiency of the public policy.

The core of the problem also consisted in matching premium level with the individual minimum willingness to accept to leave the fishery. The public authority has adjusted the administrative premium level on a trial and error basis. Unfortunately, this behaviour may lead to counter effects if it does not give fishermen the right incentives. Either the scheme provided more or less windfall gains (1991-1992 period) or it postponed the removing of the vessels, delayed the achievement of decommissioning objectives (1993-1998) and finally increased the total cost of the policy (1998-2003). An option to the current system would have been the settlement of a tendering system, in order to select the best offers according to the MAGPs objectives. However, this mechanism may yield adverse effects if there is collusion between fishermen, especially when there are a small number of applicants (cf. Nautilus (1997) for the UK experience).

However, decommissioning schemes based on premium could be very useful tools to reduce capacity in fisheries especially if they are well designed. In fisheries where there is redundant capital and the opportunity cost of capital is positive, the reduction of capacity by decommissioning schemes may be seen as necessary but not sufficient to improve the situation of the fisheries. Decommissioning policies can then contribute to fleet rationalization by getting rid of redundant capital (Guyader et al. 2004). One of the drawbacks is that the premium offered to fishermen may lead distortions in capital markets. A solution to this problem is probably to reduce the duration of the scheme and to increase the length between schemes in order to avoid the potential ratchet effects when premiums are laid down. Decommissioning schemes do not prevent common-pool resource dilemmas and the benefit of such schemes could be offset by the increasing technical efficiency and output capacity of remaining vessels. Individual fishing rights should be implemented to circumvent or reduce the "race for fish" and the consequent capital and labour "stuffing". A recent report for the French so called "académie des sciences" considered this issue, with special focus on the French fisheries (Troadec et al. 2003) (Boncoeur 2003). The operation permit has limited the entry to the fishery sector but any general system for either individual quota or licences allocation (or both) has been put in force, except for a limited number of fisheries. As a consequence, the incentives to invest in new equipments and gears in 
order to increase capacity have not been reduced. In such a condition, the French decommissioning scheme could be considered as a "danaïdes barrel" and a waste of public funds. The allocation of individual harvesting rights would have been a prerequisite to these decommissioning schemes. One can also argue that the fisheries status would be worse if nothing had been done, but this problem goes beyond the question of the policy efficiency of decommissioning schemes. 


\section{References}

Anonym. 1990. Report of an independent group of experts on the guidelines for the preparation of the multi annual guidance programmes in relation to the fishing fleets for the period 1992-1996, Internal document, European Commission, Brussels, 19.11.90 (The "Gulland" Report).

Anonym. 1996. Report of an independent group of experts to advise the European Commission on the fourth generation of multi-annual guidance programmes 26.4.96 XIV/298/96-EN (The "Lassen" Report).

Anonym. 2003. Economic Performance of Selected European Fishing Fleet, Annual Report, Concerted Action Q5CA-2001-01502, December 2003, ISBN: 90-5242-868-9, 289 p.

Boncoeur, J. Boude, J.P., Le Gallic B., Giguelay, T. andP. Le Floc'h. 1998. Assessing the Influence of Investment Subsidies on the Solvency and Viability of the Firms in the Fishing Industry: the Case of the French Fleet Operating in the English Channel Fisheries. In Hatcher, A. and K. Robinson (eds.). 1998. Overcapacity, Overcapitalisation and subsidies in European fisheries, Proceedings of the first Concerted Action Workshop on Economics and the Common Fishery Policy, UK, 28-30 October, CEMARE Miscellaneous Publication nº44 1999, 187-198.

Boncoeur, J. 2003. Le mécanisme de la surexploitation des ressources halieutiques, in Exploitation et surexploiation des ressources marines vivantes. Rapport sur la science et la technologie $\mathrm{n}^{\circ} 17$, Académie des sciences, Paris

Berthou, P. (Ed.) Daurès, F. Merrien, C. Leblond, E. Guyader, O. Jezequel, M. and S. Bermel. 2003. Synthèse des pêcheries 2002 : flotte mer du Nord-Manche-Atlantique, Ifremer report $80 \mathrm{p}$.

Daurès, F. Demanèche S., Guyader, O., Leblond E. 2003. A Methodology for the Assessment of Agregated Economic Indicators in the Fishing Sector: Estimation of a Revenue Function. Proceedings of the XVth Annual Conference of the European Association of Fisheries Economists, Brest 14-16 May 2003. http://www.ifremer.fr/eafe/

France-eco-pêche (1996) Les suites du plan puech 2 : Quand le cirpa décide ..., Octobre 1996

Frost, H., Lanters, R., Smit, J. and P. Sparre. 1995. An appraisal of the effects of the Decommissioning Schemes in the case of Denmark and the Netherlands. DIFER, South Jutland University Press, Esbjerg, Denmark, 251p.

Giguelay, T. 1999. French Decommissioning Schemes: Appraising their Place in Public Asssitance to the Fishing Industry and their Impact on Fishing Capacity, paper presented at the XIth annual conference of the European Association of Fisheries Economists, Dublin, 7-10 April 1999. 11p.

Guyader, O, and F. Daurès. 2000. Economic analysis of the impact of buyback programs and the role of financial incentives schemes: application to a limited entry French fishery. In Lindebo and Vestergaard (eds.) Proceedings of the XIIth Annual Conference of the European Association of Fisheries Economists, 65-90.

Guyader, O. Le Pellec L. and F. Daurès 2003. A Hedonic Analysis of Capital Stock in Fisheries: the Case of the Second Hand Market for Fishing Vessels (France - Atlantic area). Paper presented at the XVth Annual Conference of the European Association of Fisheries Economists, Brest 14-16 May 2003

Guyader, O., Daurès F and S. Fifas. 2004. A Bioeconomic Analysis of the Impact of Decommissioning Programs: Application to a Limited-Entry French Scallop Fishery, Forthcoming in Marine Resource Economics 
Hatcher, A. 2000. Subsidies for the European fishing fleets: the European Structural Policy for fisheries 1971-1999. Marine Policy 24:129-140.

Holden, M. 1994. The Common Fisherries Policy: Origin, Evaluation and Future. Fishing News Books, 274p.

ICES (2002) ICES Report of the Working Group on the Assessment of Southern Shelf Demersal Stcoks, ICES CM2002/ACFM:05, 943 p.

Kirkley, J. and D. Squires 1999. Measuring Capacity and Capacity Utilization in Fisheries, in D. Greboval, ed., Managing Fishing Capacity: Selected Papers on Underlying Concepts and Issues. FAO Fisheries Technical Report 386. Rome: Food and Agriculture Organization of the United Nations.

M.A.P.A. and OFIMER 2001. Bilan annuel de production 2001 des pêches et de l'aquaculture, Ministère de l'Agriculture, de l'Alimentation, de la Pêche et des Affaires Rurales (DPMA), Office National Interprofessionnel des Produits de la Mer et de l'Aquaculture, $80 \mathrm{p}$.

Morizur Y. et N. Carn, 2000. Contribution à l'évaluation et à l'évolution des puissances de pêche des fileyeurs français. Etude DGXIV-c-1 /97/033, 84 pp.

Nautilus. 1997. The economic evaluation of the fishing boats (decommissioning) schemes, Nautilus Consultants, Edinburgh, September, 106 p.

Troadec, J-P., Boncoeur, J. and J. Boucher. 2003. Le Constat, in Exploitation et surexploiation des ressources marines vivantes. Rapport sur la science et la technologie $\mathrm{n}^{\circ} 17$, Académie des sciences, Paris.

Vestergaard, N. Hoff, A. Andersen, J. Lindebo, E. Gronbaek, L. Pascoe, S. Tingley, D. Mardle, S. Guyader, O., Daurès F., Van Hoof L, De Wilde J. W. and J. Smit 2002. Measuring Capacity in Fishing Indutries using the Data Envelopment Analysis (DEA) Approach, Department of Environmental and Business Economics, University of Southern Danemark and the authors, ISBN 87-90872-05-03, 271p. 
${ }^{1}$ As underlined by Kirkley and Squires (1999), there is not a unique definition or measurement of capacity in the fisheries field. However, in economic theory, capacity is defined in terms of output-based measures.

${ }^{2}$ Historical access to foreign territorial sea is nevertheless limited to certain fleet countries according to the Common Fishery Policy regulations.

${ }^{3}$ The increase in vessels tonnage is on average more than proportional to engine power and length. This is crucial as the objective of the MAGPs were established in terms of tonnage and engine power.

${ }^{4}$ Commission Decision C(97)2363 of $11^{\text {th }}$ december 1987 and Decision C(88)2604 of $23^{\text {rd }}$ December 1988 concerning the French MAGP (1987-1991)

${ }^{5}$ Commission Decision C(95)1041/1 of the $7^{\text {th }}$ June 1996

${ }^{6}$ The vessels using dredge and eventually other no mobile gears were isolated in a specific segment for MAGP\#3

${ }^{7}$ The $7.3 \%, 9.3 \%$ and $9.0 \%$ rates were respectively applied to trawlers of less than 30 meters, to trawlers of more than 30 meters and to pelagic trawlers.

${ }^{8}$ The modified decree of the 9 January 1852 defines the basic rules governing access to the French fishing industry. Under these rules, the operation permit was first implemented by the decision 1.88 of the Comité Central de Pêches Maritimes of 22nd September 1988 and was modified by decision $1.88 / 1$ of the $19^{\text {th }}$ October $1988,1.89$ of the $30^{\text {th }}$ January $1989,3.89$ of the $30^{\text {th }}$ June 1989 and 1.91 of the $15^{\text {th }}$ March 1991. The management of the operation permit system by the so-called "interprofessional organisation" was transitory. For constitutional reasons, the system was changed under the Law n ${ }^{\circ} 91-627$ of the $3^{\text {rd }}$ July 1991 (J.O.R.F. $5^{\text {th }}$ July 1991 pp. 8761-8762). The operation permit was then defined by the decree $n^{\circ} 93-33$ of the $8^{\text {th }}$ January 1993 (JORF $10^{\text {th }}$ January 1993 pp 576-577). It was modified by the decree $\mathrm{n}^{\circ} 2000-249$ of the $15^{\text {th }}$ March 2000.

${ }^{9}$ The right to use a gear and to target a species in national water or Community waters is also subject to licence or Community special permit (P.P.S.) holding. The number of licence systems is growing and the system is managed by the so called "interprofessional organisation" at national or regional levels.

${ }^{10}$ The applicants have to put in order the debt to social security insurance and to put forward credit guarantees and mortgages.

${ }^{11}$ The contribution is limited to $3900 €$ per crew member.

12 The 1998 scheme concerned the Atlantic trawlers of less than 30 meters, dredgers, non trawlers of more than 12 meters, Mediterranean trawlers sand purse-seiners. The 1999 scheme was dedicated to trawlers of less than 30 meters and Mediterranean trawlers subject to beam trawl ban by E.C. In 2000, the applicants must belong to non trawlers of less than 12 meters and of more than 25 meters, trawlers of more than 30 meters and Mediterranean purse-seiners segments

${ }^{13}$ According to E.C. Regulation, a $1.5 \%$ decrease in premium level and per year is applied to premium level as a function of the vessel age.

${ }^{14}$ The premium level depends on the nature of the removal: exportation, vessels to be destroyed, etc. Only the case of the vessels scrapped is considered here.

${ }^{15}$ This concerns fishermen who decided to stay more than a year after withdrawing their fishing unit

${ }^{16}$ This analysis provides an estimated vessel price considering the year of transaction, the technical characteristics of the vessels and their age, the fleet belonging, the location of the transaction.

${ }^{17}$ Individual increase in administrative capacity is also possible by merging the engine power and tonnage of scraped vessels. In this case, these vessels are not elected to decommissioning schemes and the overall administrative capacity of the fleet is not changed by this process.

${ }^{18}$ Increasing fleet profitability and declining interest funding rates have probably increased the willingness to pay for vessels and consequently their price on second hand markets. 